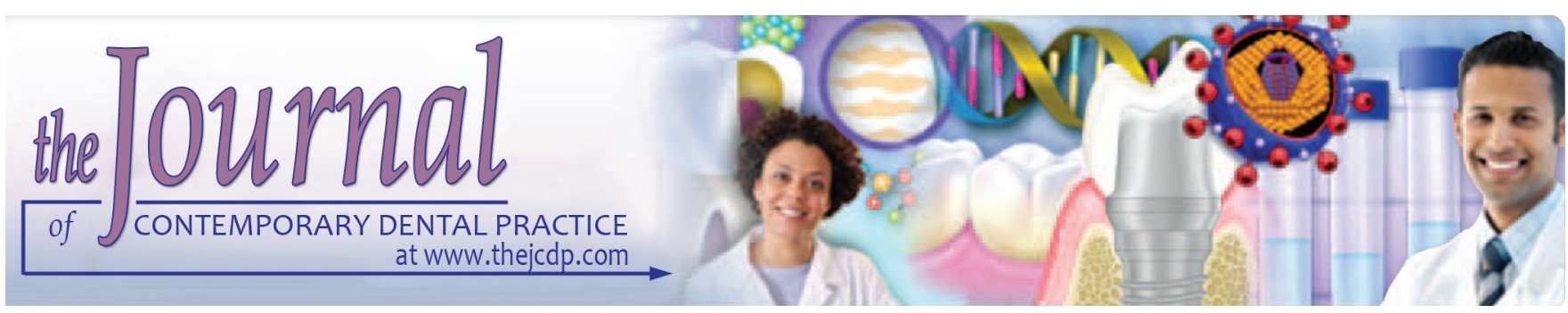

\title{
Comparative Study of the Efficacy of $4 \%$ Articaine vs $2 \%$ Lidocaine in Surgical Removal of Bilaterally Impacted Mandibular Third Molars
}

\author{
1Jyoti Mittal, ${ }^{2}$ Gurpreet Kaur, ${ }^{3}$ Harmunish S Mann, ${ }^{4}$ Samisha Narang, ${ }^{5}$ Mohit Kamra, ${ }^{6}$ Shekhar Kapoor \\ ${ }^{7}$ Madhu Sindhi, ${ }^{8}$ Ramneet Kataria
}

\begin{abstract}
Aim: The aim of this study was to evaluate the safety and efficacy of $4 \%$ articaine with epinephrine $(1: 200,000)$ vs $2 \%$ lidocaine with epinephrine (1:200,000) during surgical removal of impacted mandibular third molars.

Materials and methods: The present study was undertaken in 20 patients belonging to American Society of Anesthesiologists (ASA) class I, of the age group between 18 and 30 years with bilaterally impacted mandibular third molars. Each patient underwent similar surgical procedure. In the first appointment, the patient was randomly selected to receive either $4 \%$ articaine or $2 \%$ lidocaine (both with epinephrine 1:200,000). Intraoperative and postoperative evaluation was done for both the anesthetic solutions. Following parameters were evaluated: total volume of anesthetic solution used during the surgery, onset of action of the anesthetic agent, duration of anesthesia, duration of postoperative analgesia, incidence, type and severity of adverse
\end{abstract}

${ }^{1}$ Department of Oral and Maxillofacial Surgery, Shaheed Kartar Singh Sarabha Dental College \& Hospital, Ludhiana, Punjab India

${ }^{2}$ Department of Dental, Mohandai Oswal Hospital, Ludhiana Punjab, India

${ }^{3}$ Department of Maxillofacial Surgery, Apex Dental Hospital Ludhiana, Punjab, India

${ }^{4}$ Department of Pediatric Dentistry, Shaheed Kartar Singh Sarabha Dental College \& Hospital, Ludhiana, Punjab, India

${ }^{5}$ Department of Prosthodontics, Bhojia Dental College, Baddi Himachal Pradesh, India

${ }^{6}$ Department of Oral Medicine and Radiology, Christian Dental College, Ludhiana, Punjab, India

${ }^{7,8}$ Department of Oral and Maxillofacial Surgery, Rayat-Bahra Dental College \& Hospital, Mohali, Punjab, India

Corresponding Author: Jyoti Mittal, Department of Oral and Maxillofacial Surgery, Shaheed Kartar Singh Sarabha Dental College \& Hospital, Ludhiana, Punjab, India, Phone: +918437120001, e-mail: jyotisingla07@yahoo.com reactions, any need to reanesthetize the surgical zone and quality of anesthesia provided by the local anesthetic. Subjective pain evaluation was done with the aid of $100 \mathrm{~mm}$ length visual analog scale (VAS) both intraoperatively and postoperatively.

Results: In the present study, $4 \%$ articaine was found to have a significantly shorter onset of action than $2 \%$ lidocaine. Duration of anesthesia and postoperative analgesia of $4 \%$ articaine with epinephrine $1: 200,000$ was found to be significantly (1.44 and 1.28 times respectively) longer than $2 \%$ lidocaine with epinephrine 1:200,000. But no significant difference was found in other parameters.

Conclusion: $4 \%$ articaine in comparison with $2 \%$ lidocaine (both with epinephrine 1:200,000) provided a shorter onset of action and longer duration of anesthesia.

Clinical significance: No significant difference was recorded in the anesthetic efficacy between the two solutions.

Keywords: Articaine, Impacted mandibular third molar, Inferior alveolar nerve block, Lidocaine, Mandibular nerve block.

How to cite this article: Mittal J, Kaur G, Mann HS, Narang S, Kamra M, Kapoor S, Sindhi M, Kataria R. Comparative Study of the Efficacy of $4 \%$ Articaine vs $2 \%$ Lidocaine in Surgical Removal of Bilaterally Impacted Mandibular Third Molars. J Contemp Dent Pract 2018;19(6):743-748.

Source of support: Nil

Conflict of interest: None

\section{INTRODUCTION}

Removal of impacted third molar is the most commonly performed surgical procedure by oral and maxillofacial surgeons. Local anesthetic agents are the mainstay of intraoperative pain control for most office-based oral surgical procedures. Their introduction has revolutionized the practice of dentistry and allowed for a safer pain-free surgical experience. The selection of local anesthetic agent mainly depends upon its potency, latency, and duration. Lidocaine, amide type revolutionized pain control 
in regional anesthesia by replacing procaine and other closely related ester-type compounds. ${ }^{1}$ Lidocaine as compared with procaine, is more potent, with significantly rapid onset of action, profound anesthesia, and longer duration of action. When associated with adrenaline, it has short onset (2-3 minutes) and intermediate duration (60 minutes at pulpal level, 180-300 minutes in soft tissues). ${ }^{1}$ Because of its potency, safety, and effectiveness, lidocaine has become the gold standard for comparison among the newer agents.

Newer amide local anesthetic, articaine, is a safe and effective anesthetic used in clinical dentistry since the last two decades. Due to the presence of a thiophenic ring with additional ester group in substitution with aromatic ring, the chemical structure has different properties as compared with other local anesthetic. Because of this, articaine provides increased lipid solubility, intrinsic potency (1.5 times greater than that of lidocaine), as well as greater plasma protein binding (approximately 95\%). ${ }^{2,3}$ The duration of anesthesia of $4 \%$ articaine with epinephrine $(1: 200,000)$ for mandibular block directly depends upon its protein-binding capacity (45-60 minutes at pulpal level and 120-300 minutes on soft tissues) and onset of action is 2 to 3 minutes. ${ }^{1}$ Thus, a study was planned to evaluate the safety and efficacy of $4 \%$ articaine with epinephrine $(1: 200,000)$ vs $2 \%$ lidocaine with epinephrine $(1: 200,000)$ during surgical removal of impacted mandibular third molars.

\section{MATERIALS AND METHODS}

The present study was performed in the Department of Oral and Maxillofacial Surgery at Sri Guru Ram Das Institute of Dental Sciences and Research, Amritsar, on 20 patients, with bilateral impacted mandibular third molars. Patients belonging to ASA class I, of the age group between 18 and 30 years with no systemic illness and having healthy dental and periodontal status were included.

\section{Methodology}

A standardized protocol was followed for the surgical removal of third molars. Surgery was carried out under strict aseptic conditions. Each patient underwent similar surgical procedure for the removal of bilateral impacted third molar in two separate visits. The time interval between the two surgical procedures in a single patient was at least 4 weeks. For the first time, patients were selected to receive either $4 \%$ articaine or $2 \%$ lidocaine (both with epinephrine 1:200,000) randomly. At the subsequent surgery, other local anesthetic agent was administered in a crossed manner.

- Each patient received a total of $3.6 \mathrm{~mL}$ of anesthetic solution; $1.8 \mathrm{~mL}$ of the solution was used for achieving regional anesthetic blockade of inferior alveolar nerve and lingual nerve. After adequate anesthesia had been achieved, another $1.8 \mathrm{~mL}$ solution was used for buccal nerve anesthesia and infiltration in the mucosa for the purpose of hemostasis in both the groups. If a patient complains of pain during surgery, additional local anesthetic was injected. A bayonet-shaped flap was made on the surgical side. After tooth removal, the surgical site was thoroughly irrigated, hemostasis was achieved, and suturing was done using $3 / 0$ silk.

- Patients were observed in the clinic for the first postoperative hour.

- The duration of surgery was noted from the time of placement of the incision till the time when the last suture was given.

Patients were prescribed Tab. Augmentin $625 \mathrm{mg}$ TDS (Amoxicillin $500 \mathrm{mg}$ + Clavulanic acid $125 \mathrm{mg}$; GlaxoSmithKline) and Tab. Brufen $600 \mathrm{mg}$ TDS (Ibuprofen $600 \mathrm{mg}$; Abbott India), for 5 days postoperatively. Tab. paracetamol $500 \mathrm{mg}$ was used as rescue analgesic medicine and the patients were asked to note down the number of tablets required, if any, to relieve pain.

\section{Intraoperative and Postoperative Evaluation}

The following parameters were assessed:

- Total amount (in $\mathrm{mL}$ ) of anesthetic solution used during the surgery

- Onset of action of anesthetic agent, evaluated as tingling and numbness of lower lip, corresponding half of the tongue and mucosa (reported by the patient).

- The duration of anesthesia was recorded as the time from initial patient perception of the anesthetic effect to the moment when the effect began to fade.

- Need to reanesthetize the surgical zone: specifying the amount of anesthetic solution used and the technique of injection.

- Duration of postoperative analgesia (in minutes) evaluated as the period between the end of the surgery and the ingestion of the first brufen tablet for pain relief.

- Incidence, type, and severity of adverse reactions: Any findings suggestive of effect on cardiovascular and central nervous system like nervousness, dizziness, tremors, blurred eyes, etc., during the surgery and during the first postoperative hour.

- Quality of the anesthesia provided by the local anesthetic during the surgery and evaluated by the surgeon, according to the eight-point category rating scale (Table 1), as described by Sisk. ${ }^{4}$

- Subjective pain evaluation was done with the aid of a $100 \mathrm{~mm}$ length VAS with markings between 1 and $25 \mathrm{~mm}$ as mild pain, between 26 and 
Table 1: Eight-point category rating scale for evaluation of quality of anesthesia

\begin{tabular}{|c|c|}
\hline Category & Patient response during extraction \\
\hline Successful (1) & No pain throughout \\
\hline Successful (2) & $\begin{array}{l}\text { Some pain during procedure, but } \\
\text { reinjection not necessary after beginning } \\
\text { of surgery }\end{array}$ \\
\hline Successful (3) & $\begin{array}{l}\text { Pain during procedure beginning after } \\
\text { first injection. No pain after second } \\
\text { injection }\end{array}$ \\
\hline Limited success (4) & $\begin{array}{l}\text { Pain during procedure beginning after } \\
\text { first injection. Pain also during procedure } \\
\text { after second injection, but procedure } \\
\text { completed without third injection }\end{array}$ \\
\hline Limited success (5) & $\begin{array}{l}\text { Pain during procedure beginning after two } \\
\text { injections, but surgery completed without } \\
\text { third injection }\end{array}$ \\
\hline Failure (6) & $\begin{array}{l}\text { Pain during procedure after first injection. } \\
\text { Pain also during procedure after second } \\
\text { injection. Third injection required }\end{array}$ \\
\hline Failure (7) & $\begin{array}{l}\text { Pain during procedure beginning after two } \\
\text { injections. Third injection required }\end{array}$ \\
\hline Failure (8) & $\begin{array}{l}\text { No anesthesia after two injections. Third } \\
\text { injection required or treatment suspended }\end{array}$ \\
\hline
\end{tabular}

$50 \mathrm{~mm}$ as moderate pain, between 51 and $75 \mathrm{~mm}$ as intense pain, and between 76 and $100 \mathrm{~mm}$ as unbearable pain.

- Each patient scored pain intensity during the surgery and after the operation. Subjects recorded the intensity of postoperative pain at 15-minute intervals till the anesthetic effect had worn off.

- Total amount of rescue analgesic medication (paracetamol) needed during the postoperative period.

- Systolic, diastolic, and mean arterial pressure, heart rate, and oxygen saturation were noted during the surgery and after suturing. During the surgery, two measurements were made: one immediately after the regional anesthetic blockage and another 5 minutes later.
The data obtained were analyzed statistically to evaluate the efficacy of both the local anesthetic agents used during surgical removal of mandibular third molars.

\section{Statement of Institutional Review Board}

This study followed Declaration of Helsinki on medical protocol and ethics and the regional Ethical Review Board and was approved by the Institutional Review Board.

\section{RESULTS}

In the present study, comparison of mean volume of both the anesthetic solutions used showed a statistically nonsignificant difference. Volume of lidocaine used was slightly more $(3.815 \mathrm{~mL})$ as compared with the articaine (3.725 mL). In our study, statistically significant difference was found regarding the mean onset of action ( $p$-value 0.011) as illustrated in Table 2. The mean duration of anesthetic effect of articaine (141.20 \pm 36.15 minutes) was significantly longer ( $p$-value $<0.001$ ), and articaine provided a significantly longer period of postoperative analgesia (p-value 0.017), ${ }^{*}$ as given in Table 2 .

Quality of anesthesia was scored as 1 in $85 \%$ of patients in articaine group and 65\% patients in the lidocaine group. In our study, no significant difference in the mean perioperative and postoperative pain scores was observed between both the anesthetic solutions as shown in Table 3 .

In our study, there were no consistent changes in vital signs (systolic blood pressure, diastolic blood pressure, and mean arterial pressure, heart rate, and oxygen saturation) observed at baseline, right after injection of the local anesthetic, 5 minutes later, or at the end of the surgical procedure for both treatment groups. Although transient increase and decrease in blood pressure, heart rate, and oxygen saturation were observed, these changes were not clinically and statistically significant between both the anesthetic groups as illustrated in Tables 4 to 6 .

Table 2: Evaluation of onset of action, duration of anesthesia, and postoperative analgesia

\begin{tabular}{|c|c|c|c|c|c|}
\hline \multirow[b]{2}{*}{ Parameters } & \multicolumn{2}{|c|}{ Articaine $(n=20)$} & \multicolumn{2}{|c|}{ Lidocaine $(n=20)$} & \multirow[b]{2}{*}{$p$-value } \\
\hline & Mean $\pm S D$ & Range & Mean $\pm S D$ & Range & \\
\hline Onset of action (seconds) & $54.10 \pm 20.99$ & $25-107$ & $73.50 \pm 24.64$ & $37-116$ & $0.011^{*}$ \\
\hline Duration of anesthesia (minutes) & $141.20 \pm 36.15$ & $78-244$ & $97.85 \pm 24.86$ & $60-150$ & $<0.001^{* *}$ \\
\hline Duration of postoperative analgesia (minutes) & $231.70 \pm 78.89$ & $127-415$ & $181.50 \pm 42.28$ & $120-310$ & $0.017^{*}$ \\
\hline
\end{tabular}

*Significant; **Highly significant; SD: Standard deviation; In all the three parameters (onset of action, duration of anesthesia, and postoperative analgesia) data were analyzed using unpaired " $t$ " test

Table 3: Evaluation of pain using VAS

\begin{tabular}{|c|c|c|c|c|c|}
\hline \multirow[b]{2}{*}{ Parameters } & \multicolumn{2}{|c|}{ Articaine $(n=20)$} & \multicolumn{2}{|c|}{ Lidocaine $(n=20)$} & \multirow[b]{2}{*}{$p$-value } \\
\hline & Mean $\pm S D$ & Range & Mean $\pm S D$ & Range & \\
\hline Intraoperative pain score (mm) & $4.25 \pm 12.28$ & $0-40$ & $9.00 \pm 15.01$ & $0-40$ & $0.280 \mathrm{NS}$ \\
\hline Postoperative pain score $(\mathrm{mm})$ & $13.00 \pm 5.94$ & $0-20$ & $14.75 \pm 6.38$ & $0-30$ & $0.375 \mathrm{NS}$ \\
\hline
\end{tabular}

NS: nonsignificant; $n=$ Total no. of patients; SD: Standard deviation; The data were analyzed using unpaired t-test and no statistically significant difference was found $(p=0.375)$ in the mean postoperative pain scores in both the anesthetic groups 
Table 4: Evaluation of systolic blood pressure

\begin{tabular}{|c|c|c|c|c|c|c|c|}
\hline \multirow[b]{2}{*}{ Time } & \multicolumn{3}{|c|}{ Articaine } & \multicolumn{3}{|c|}{ Lidocaine } & \multirow{2}{*}{$\begin{array}{l}\text { Articaine vs } \\
\text { lidocaine } \\
p \text {-value }\end{array}$} \\
\hline & $\begin{array}{l}\text { Mean } \pm S D \\
(m m ~ H g)\end{array}$ & $\begin{array}{l}\text { Mean difference } \\
(\mathrm{mm} \mathrm{Hg})\end{array}$ & $p$-value & $\begin{array}{l}\text { Mean } \pm S D \\
(m m ~ H g)\end{array}$ & $\begin{array}{l}\text { Mean difference } \\
(\mathrm{mm} \mathrm{Hg})\end{array}$ & $p$-value & \\
\hline Before surgery & $114.40 \pm 9.92$ & 0.80 & $0.119 \mathrm{NS}$ & $116.95 \pm 10.45$ & 0.70 & $0.201 \mathrm{NS}$ & $0.434 \mathrm{NS}$ \\
\hline Immediately after LA & $115.20 \pm 10.21$ & & & $117.65 \pm 11.22$ & & & $0.475 \mathrm{NS}$ \\
\hline 5 min later & $115.20 \pm 10.18$ & 0.80 & $0.176 \mathrm{NS}$ & $117.15 \pm 10.99$ & 0.20 & $0.781 \mathrm{NS}$ & $0.564 \mathrm{NS}$ \\
\hline After suturing & $114.80 \pm 10.01$ & 0.40 & $0.359 \mathrm{NS}$ & $116.85 \pm 9.18$ & 0.10 & $0.853 \mathrm{NS}$ & $0.504 \mathrm{NS}$ \\
\hline
\end{tabular}

LA: Local anesthesia; NS: Nonsignificant; SD: Standard deviation; The data were analyzed by using paired t-test but the intragroup variations in mean systolic blood pressure were found to be statistically nonsignificant $(p>0.05)$. The intergroup comparison of mean systolic blood pressure of articaine vs lidocaine was analyzed using unpaired t-test and the difference in the mean systolic blood pressure was found to be statistically nonsignificant $(p>0.05)$ between both the anesthetic groups

Table 5: Evaluation of mean arterial pressure

\begin{tabular}{|c|c|c|c|c|c|c|c|}
\hline \multirow[b]{2}{*}{ Time } & \multicolumn{3}{|c|}{ Articaine } & \multicolumn{3}{|c|}{ Lidocaine } & \multirow{2}{*}{$\begin{array}{l}\text { Articaine vs } \\
\text { lidocaine } \\
p \text {-value }\end{array}$} \\
\hline & Mean $\pm S D$ & Mean difference & $p$-value & Mean $\pm S D$ & Mean difference & $p$-value & \\
\hline Before surgery & $91.80 \pm 6.34$ & 0.066 & $0.846 \mathrm{NS}$ & $94.05 \pm 8.82$ & 0.166 & $0.718 \mathrm{NS}$ & $0.360 \mathrm{NS}$ \\
\hline Immediately after LA & $91.87 \pm 6.04$ & & & $94.22 \pm 8.02$ & & & $0.302 \mathrm{NS}$ \\
\hline 5 min later & $92.00 \pm 6.49$ & 0.200 & 0.664 NS & $94.05 \pm 8.81$ & 0 & $1.000 \mathrm{NS}$ & $0.408 \mathrm{NS}$ \\
\hline After suturing & $92.27 \pm 6.72$ & 0.467 & $0.196 \mathrm{NS}$ & $94.02 \pm 8.36$ & 0.03 & $0.924 \mathrm{NS}$ & $0.470 \mathrm{NS}$ \\
\hline
\end{tabular}

LA: Local anesthesia; NS: Nonsignificant; SD: Standard deviation; The intragroup evaluation of mean arterial pressure for both the anesthetic solutions was analyzed using paired t-test and the difference in mean arterial pressure was found to be statistically nonsignificant $(p>0.05)$ for both the anesthetic solutions

Table 6: Comparison of heart rate

\begin{tabular}{|c|c|c|c|c|c|c|c|}
\hline \multirow[b]{2}{*}{ Time } & \multicolumn{3}{|c|}{ Articaine } & \multicolumn{3}{|c|}{ Lidocaine } & \multirow{2}{*}{$\begin{array}{l}\text { Articaine vs } \\
\text { lidocaine } \\
p \text {-value }\end{array}$} \\
\hline & $\begin{array}{l}\text { Mean } \pm S D \\
\text { (beats/min) }\end{array}$ & $\begin{array}{l}\text { Mean difference } \\
\text { (beats/min) }\end{array}$ & $p$-value & $\begin{array}{l}\text { Mean } \pm S D \\
\text { (beats/min) }\end{array}$ & $\begin{array}{l}\text { Mean difference } \\
\text { (beats/min) }\end{array}$ & $p$-value & \\
\hline Before surgery & $88.10 \pm 11.89$ & 3.25 & $0.094 \mathrm{NS}$ & $87.70 \pm 12.89$ & 4.40 & $0.017 \mathrm{NS}$ & $0.919 \mathrm{NS}$ \\
\hline Immediately after LA & $91.35 \pm 13.29$ & & & $92.10 \pm 13.31$ & & & $0.859 \mathrm{NS}$ \\
\hline 5 min later & $91.95 \pm 12.01$ & 3.85 & $0.018 \mathrm{NS}$ & $92.35 \pm 13.98$ & 4.65 & $0.046 \mathrm{NS}$ & $0.923 \mathrm{NS}$ \\
\hline After suturing & $87.20 \pm 12.59$ & 0.90 & $0.562 \mathrm{NS}$ & $89.15 \pm 11.06$ & 1.45 & $0.482 \mathrm{NS}$ & $0.606 \mathrm{NS}$ \\
\hline
\end{tabular}

LA: Local anesthesia; NS: Nonsignificant; SD: Standard deviation; The evaluation of heart rate, before surgery, during surgery, and after suturing for both the anesthetic solutions is shown

\section{DISCUSSION}

The comparison of the mean volume of both the anesthetic solutions used showed a statistically nonsignificant difference, although the volume of lidocaine used was slightly more $(3.815 \mathrm{~mL})$ as compared with the articaine (3.725 mL). This is explained by the fact that additional anesthesia was required in more number of patients of lidocaine group (25\%) as compared with (10\%) patients of articaine group. Our results are supported by Rebolledo et $\mathrm{al}^{3}$ who found that the average volume of $2 \%$ lidocaine with epinephrine 1:100,000 was 1.7 times greater than that of $4 \%$ articaine with epinephrine 1:100,000 but the results were found to be statistically nonsignificant. They explained this difference in volume based on the fact that the number of repeat anesthetic procedures was greater when using $2 \%$ lidocaine as compared with $4 \%$ articaine group. Malamed et $\mathrm{al}^{2}$ also reported a nonsignificant difference regarding the volume of $2 \%$ lidocaine with epinephrine 1:100,000 (2.6 mL \pm 0.09 Standard error of mean (SEM), $4.5 \mathrm{~mL} \pm 0.21 \mathrm{SEM})$ and $4 \%$ articaine 1:100,000 (2.5 mL $\pm 0.07 \mathrm{SEM}, 4.2 \mathrm{~mL} \pm 0.15 \mathrm{SEM})$, when used for simple and complex procedures respectively.

Various factors affect the onset of anesthetic solution, such as the intrinsic properties of the drug, technique used, and its pKa value; smaller the $\mathrm{pKa}$, shorter the latency. As the articaine has less $\mathrm{pKa}$ value as compared with the lidocaine, it has a short latent period. ${ }^{5}$ In our study, the mean onset of action of $4 \%$ articaine with epinephrine $(1: 200,000)$ was found to be 54.10 seconds (0.90 minutes) as compared with the 73.50 seconds (1.22 minutes) for $2 \%$ lidocaine with epinephrine $(1: 200,000)$. A statistically significant difference was found regarding the mean onset of action between the articaine group (54.10 seconds) and lignocaine (73.50 seconds), meaning thereby a higher latency period for lignocaine as compared with articaine. Our results are in agreement with Rebolledo et $\mathrm{al}^{3}{ }^{3}$ who also found a higher latency period for $2 \%$ lidocaine with epinephrine 1:100,000 (1.25 minutes) 
as compared with $4 \%$ articaine with epinephrine 1:100,000 (0.93 minutes). Further, Gregorio et $\mathrm{al}^{6}$ found that the $4 \%$ articaine with epinephrine 1:200,000 has a shorter mean time of onset (1.66 minutes) as compared with $0.5 \%$ bupivacaine with epinephrine 1:200,000 (2.51 minutes). Cowan $^{7}$ in a comparative study of $4 \%$ articaine and rest of amide local anesthetics found the latency of articaine as 1.48 minutes.

The duration of anesthesia depends upon its degree of protein binding, injection site, and the concentration of vasoconstrictor added in the solution. Articaine has the greatest protein-binding values among other amides. In the literature, the protein-binding capacity for lidocaine and articaine is 65 and $95 \%$ respectively. ${ }^{8}$

In the present study, the mean duration of anesthesia of $4 \%$ articaine with epinephrine 1:200,000 (141.20 \pm 36.15 minutes) was significantly longer as compared with $2 \%$ lidocaine with epinephrine 1:200,000 (97.85 \pm 24.86 minutes). Ram and Amir ${ }^{8}$ compared $4 \%$ articaine with epinephrine 1:200,000 with 2\% lidocaine with epinephrine 1:100,000 in pediatric dental patients and found that the duration of soft tissues anesthesia was significantly longer for articaine (223 minutes) than for lidocaine (180 minutes). Rebolledo et $\mathrm{al}^{3}$ compared the anesthetic efficacy of $4 \%$ articaine with that of $2 \%$ lidocaine, both with epinephrine 1:100,000 and also found that the mean duration of anesthetic effect of articaine was significantly longer than the lidocaine group.

Postoperative pain control has been a point of debate since many years because it interferes with patients' quality of life. Our results demonstrated that $4 \%$ articaine provides a significantly longer period of postoperative analgesia ( $231.70 \pm 78.89$ minutes), which is explained by its ability to readily diffuse through due to the presence of a thiophene group in the molecules, which increases its lipid solubility. Our findings regarding postoperative analgesia with the use of articaine are in agreement with the findings of Colombini et al, ${ }^{9}$ Santos et al, ${ }^{10}$ and Gregorio et al. ${ }^{6}$ Our results with the use of lidocaine are supported by Giovannitti and Bennett , ${ }_{1}^{11}$ who found that postoperative analgesia lasted for 192.5 minutes.

Quality of anesthesia was evaluated according to the eight-point category rating scale in our study. Our results indicated that both the local anesthetics were successful in providing the anesthesia during surgery. However, $4 \%$ articaine with epinephrine 1:200,000 was more successful (quality of anesthesia was scored as 1 in $85 \%$ of patients in articaine group as compared with $65 \%$ patients in lidocaine group) as compared with $2 \%$ lidocaine with epinephrine 1:200,000. Our findings for the lidocaine are similar to that of Sisk, ${ }^{4}$ who also reported that the $2 \%$ lidocaine with epinephrine 1:100,000 was successful in providing the anesthesia during the surgery. Further,
Giovannitti and Bennett ${ }^{11}$ reported that the quality of anesthesia produced by $2 \%$ lidocaine with epinephrine $1: 100,000$ was rated as successful in all the 28 inferior alveolar nerve blocks, given in their study. Also comparable results have been reported by Gregorio et al, ${ }^{6}$ and Santos et al, ${ }^{10}$ who found that the mean scores for quality of anesthesia were close to 1 with the use of $4 \%$ articaine with epinephrine 1:200,000.

In the present study, subjective evaluation of both the intraoperative and postoperative pain was made by means of a $100-m m$ VAS. The VAS has been used by many authors for the subjective evaluation of pain. 2,3,9,12-15

The primary end point of our study was the subjective evaluation of pain during the surgical procedure. In our study, the anesthetic efficacy of articaine was demonstrated by the low mean intraoperative pain scores than the lidocaine, but no significant difference in the mean perioperative pain scores was observed between both the anesthetic solutions. Our results are supported by Malamed et $\mathrm{al}^{2,16}$ and Rebolledo et $\mathrm{al}^{3}$ who in their study also found no significant difference in the mean intraoperative VAS pain scores.

In this study, the postoperative pain evaluation also showed no significant difference between both the anesthetic groups. Our results are supported by Oliveira et $\mathrm{al}^{13}$ and Rosenberg et $\mathrm{al}^{14}$ who also observed no statistically significant differences in the VAS scores of postoperative pain with the use of $4 \%$ articaine and $2 \%$ lidocaine (both with epinephrine 1:100,000). Our findings for articaine are in agreement with Colombini et $\mathrm{al}^{9}$ who also reported the low scores of pain (under $10 \mathrm{~mm}$ ) in their comparative study of efficacy of $4 \%$ articaine vs $2 \%$ mepivacaine both with epinephrine $(1: 100,000)$ in postoperative analgesia for lower third molar removal.

Evaluation of vital parameters (oxygen saturation, systolic and diastolic blood pressure, mean arterial pressure, and heart rate) is important during any surgical procedure. Basic monitoring provides essential information for assessing the principal vital signs, both circulatory and respiratory, and fundamentally comprises the control of blood pressure (through sphygmomanometry), heart rate, and rhythm. ${ }^{17}$

In dentistry, local anesthetics produce limited and safe hemodynamic effects. The rates of blood pressure and serum oxygen saturation are due to endogenous catecholamines or because of adrenaline used in local anesthetic. ${ }^{18}$

In our study, vital parameters were analyzed before surgery, during surgery, and after suturing. No consistent changes in vital signs were observed at baseline, after injection, 5 minutes later, or at the end of the surgical procedure for both treatment groups. Although transient changes were observed, these changes were not clinically and statistically significant between both the anesthetic 
groups. Our results are in agreement with the study conducted by Malamed et $\mathrm{al}^{16}$ and Santos et $\mathrm{al}_{1}^{10}$ who compared the use of $4 \%$ articaine in association with 1:100,000 or 1:200,000 epinephrine in lower third molar removal. They also observed transient changes in hemodynamic parameters which were neither clinically significant nor attributable to the type of anesthetic solution used. Vasconcellos et $\mathrm{al}^{18}$ studied the effect of $2 \%$ lidocaine with $1: 100,000$ adrenaline, $3 \%$ prilocaine with $0.03 \mathrm{IU}$ felypres$\sin , 2 \%$ mepivacaine, and $4 \%$ articaine both with $1: 100,000$ adrenaline in patients undergoing surgical removal of third molars and evaluated the changes in heart rate, oxygen saturation and systolic, diastolic, and mean blood pressure. Significant decrease in the diastolic blood pressure with lidocaine and increase in systolic blood pressure with mepivacaine and articaine were noted. A significant increase in heart rate from baseline to postanesthesia and a decrease in heart rate from postanesthesia to end of surgery were observed in all the groups and with all the anesthetic solutions except prilocaine. However, all the hemodynamic parameters returned to normal with no need for any further treatment.

Another parameter compared in our study was the incidence, type, and severity of adverse reactions during surgery and during the first postoperative hour. In the present study, no adverse reactions were observed perioperatively and postoperatively for both the anesthetic solutions. Colombini et $\mathrm{al}^{9}$ and Santos et $\mathrm{al}^{10}$ have also reported no adverse reactions with the use of articaine as a local anesthetic. Giovannitti and Bennett ${ }^{11}$ in their study on the use of $2 \%$ lidocaine with epinephrine 1:100,000 in surgical removal of third molars also did not report any side effects or adverse reactions of the local anesthetic agent. Our results are not supported by Malamed et $\mathrm{al}^{16}$; they, however, have reported adverse reactions both with articaine and lidocaine including paresthesia, hyperesthesia, headache, infection, rash, pain, and dizziness.

\section{REFERENCES}

1. Malamed, SF. Hand book of local anesthesia. 5th ed. St. Louis (MO): CV Mosby; 2004.

2. Malamed SF, Gagnon S, Leblanc D. Efficacy of articaine: a new amide local anaesthetic. J Am Dent Assoc 2000 May;131(5):635-642.

3. Rebolledo AS, Molina ED, Aytes LB, Escoda CG. Comparative study of the anesthetic efficacy of $4 \%$ articaine versus $2 \%$ lidocaine in inferior alveolar nerve block during surgical extraction of impacted lower third molars. Med Oral Patol Oral Cir Bucal 2007 Mar;12(2):139-144.

4. Sisk AL. Comparison of etidocaine and lidocaine for control of intra-operative and post-operative bleeding and pain. J Oral Maxillofac Surg 1986 Jan;44(1):16-20.
5. Berlin J, Nusstein J, Reader A, Beck M, Weaver J. Efficacy of articaine and lidocaine in a primary intraligamentary injection administered with a computer-controlled local anesthetic delivery system. Oral Surg Oral Med Oral Pathol Oral Radiol Endod 2005 Mar;99(3):361-366.

6. Gregorio LV, Giglio FP, Sakai VT, Modena KC, Colombini BL, Calvo AM, Sipert CR, Dionísio TJ, Lauris JR, Faria FA, et al. A comparison of the clinical anesthetic efficacy of $4 \%$ articaine and $0.5 \%$ bupivacaine (both with 1:200,000 epinephrine) for lower third molar removal. Oral Surg Oral Med Oral Pathol Oral Radiol Endod 2008 Jul;106(1):19-28.

7. Cowan A. Clinical assessment of a new local anesthetic agent-carticaine. Oral Surg Oral Med Oral Pathol 1977 Feb;43(2):174-180.

8. Ram D, Amir E. Comparison of articaine $4 \%$ and lidocaine $2 \%$ in paediatric dental patients. Int J Paed Dent 2006 Jul;16(4):252-256.

9. Colombini BL, Modena KC, Calvo AM, Sakai VT, Giglio FP, Dionisio TJ, Trindade AS Jr, Lauris JR, Santos CF. Articaine and mepivacaine efficacy in postoperative analgesia for lower third molar removal: a double-blind, randomized, crossover study. Oral Surg Oral Med Oral Pathol Oral Radiol Endod 2006 Aug;102(2):169-174.

10. Santos CF, Modena KC, Giglio FP, Sakai VT, Calvo AM, Colombini BL, Sipert CR, Dionísio TJ, Faria FA, Trindade AS Jr, et al. Epinephrine concentration $(1: 100,000$ or 1:200,000) does not affect the clinical efficacy of $4 \%$ articaine for lower third molar removal: a double-blind randomized, crossover study. J Oral Maxillofac Srug 2007 Dec;65(12):2445-2452.

11. Giovannitti JA, Bennett CR. The effectiveness of $1.5 \%$ etidocaine $\mathrm{HCl}$ with epinephrine 1:200,000 and 2\% lidocaine $\mathrm{HCl}$ with epinephrine 1:100,000 in oral surgery: a clinical comparison. J Am Dent Assoc 1983 Oct;107(4):616-618.

12. Malamed SF, Gagnon S, Leblanc D. A comparison between articaine HCL and lidocaine HCL in pediatric dental patients. Pediatr Dent 2000 Jul-Aug;22(4):307-311.

13. Oliveira PC, Volpato MC, Ramacciato JC, Ranali J. Articaine and lignocaine efficiency in infiltration anesthesia: a pilot study. Br Dent J 2004 Jul;197(1):45-46.

14. Rosenberg PA, Amin KG, Zibari Y, Lin LM. Comparison of $4 \%$ articaine with 1:100,000 epinephrine and 2\% lidocaine with 1:100,000 epinephrine when used as a supplemental anesthetic. J Endod 2007 Apr;33(4):403-405.

15. Fan S, Chen WL, Yang ZH, Huang ZQ. Comparison of the efficiencies of permanent maxillary tooth removal performed with single buccal infiltration versus routine buccal and palatal injection. Oral Surg Oral Med Oral Pathol Oral Radiol Endod 2009 Mar;107(3):359-363.

16. Malamed SF, Gagnon S, Leblanc D. Articaine hydrochloride: a study of safety of a new amide local anesthetic. J Am Dent Assoc 2001 Feb;132(2):177-185.

17. Alemany-Martínez A, Valmaseda-Castellón E, Berini-Aytés L, Gay-Escoda C. Hemodynamic changes during the surgical removal of lower third molar. J Oral Maxillofac Srug 2008 Mar;66(3):453-461.

18. Vasconcellos RJ, Vasconcelos BC, Genu PR. Influence of local anesthetics with adrenaline 1:100.000 in basic vital constants during third molar surgery. Med Oral Pathol Oral Cir Bucal 2008 Jul;13(7):E431-E437. 